\title{
Genetic polymorphisms in cyclin D1 are associated with risk of renal cell cancer in the Chinese population
}

\author{
Jianxin Xue ${ }^{1,2, *}$, Zhiqiang Qin ${ }^{1, *}$, Xiao Li $^{3, *}$, Jianzhong Zhang ${ }^{1}$, Yuxiao Zheng ${ }^{1}$, \\ Weizhang $\mathrm{Xu}^{4}$, Qiang $\mathrm{Cao}^{1}$ and Zengjun Wang ${ }^{1}$ \\ ${ }^{1}$ Department of Urology, The First Affiliated Hospital of Nanjing Medical University, Nanjing, 210029, China \\ ${ }^{2}$ Department of Urology, The Second Affiliated Hospital of Southeast University, Nanjing, 210003, China \\ ${ }^{3}$ Department of Urologic Surgery, The Affiliated Cancer Hospital of Jiangsu Province of Nanjing Medical University, Nanjing, \\ 210009, China \\ ${ }^{4}$ Department of Thoracic Surgery, Nanjing Medical University Affiliated Cancer Hospital, Jiangsu Key Laboratory of Molecular \\ and Translational Cancer Research, Cancer Institute of Jiangsu Province, Nanjing, 210009, China \\ *These authors have contributed equally to this work \\ Correspondence to: Zengjun Wang, email: zengjunwang@njmu.edu.cn \\ Qiang Cao, email: qiang_cao@126.com \\ Keywords: cyclin D1, polymorphism, renal cell cancer, genetic susceptibility \\ Received: May 16, $2017 \quad$ Accepted: August 06, $2017 \quad$ Published: September 08, 2017 \\ Copyright: Xue et al. This is an open-access article distributed under the terms of the Creative Commons Attribution License 3.0 \\ (CC BY 3.0), which permits unrestricted use, distribution, and reproduction in any medium, provided the original author and source \\ are credited.
}

\section{ABSTRACT}

Recently, the functional polymorphisms in Cyclin D1 (CCND1) have been shown the potential influence to risk of renal cell cancer (RCC). Therefore, the present study was performed to investigate whether these polymorphisms could influence the susceptibility of RCC. Four potentially functional polymorphisms in CCND1 (rs1944129, rs7177, rs9344 and rs678653) were genotyped in this hospital-based case-control study, comprising of 1,488 RCC patients and 1,677 cancer-free controls in a Chinese population by the TaqMan assay. The logistic regression was used to assess the associations between CCND1 polymorphisms and the risk of RCC. We found the genotype and allele frequency distribution of rs1944129 and rs7177 were significantly associated with risk of $\operatorname{RCC}(P=0.015$ and $P=0.018$, respectively $)$. The analysis of combined risk alleles revealed that patients with 2-4 risk alleles showed an elevated risk of RCC compared to those with $0-1$ risk alleles $(O R=1.35,95 \% \mathrm{CI}=1.15-1.58$, $P<0.001$ ). Furthermore, compared with the genotypes containing $G$ allele (AG and GG), the patients carrying the AA genotype in CCND1 rs1944129 polymorphism had a significantly greater prevalence of high clinical stage disease (OR $=0.56,95 \% \mathrm{CI}$ $=0.33-0.94, P=0.029$ ). These results suggested that these CCND1 polymorphisms rs1944129 and rs7177 might contribute to the susceptibility of RCC in the Chinese population.

\section{INTRODUCTION}

As a complex-trait disease, renal cell cancer (RCC) is considered as one of the most common type of the kidney malignancy with a high prevalence in older men (>70 years of age) and is estimated to account for approximately $90 \%$ of all renal malignancies [1-4]. Besides, the incidence of RCC is steadily increasing and indicates variation among different populations [4]. The accurate etiology of RCC is not completely well-understood, although its development is involved in a series of complex environmental and lifestyle factors, including obesity, ethnicity, age, tobacco smoking, alcohol consumption, diabetes, hypertension, occupational exposures to chemicals and family history $[3,5-8]$. However, recent studies have demonstrated that 
genetic variations, particularly single-nucleotide genetic polymorphisms (SNPs) might contribute greatly to the occurrence of RCC [9].

As a member of the D-type cyclin family, cyclin D1 (CCND1) was a proto-oncogene and a good biomarker for tumor progression, found to be deregulated in several cancers, including RCC [10]. CCND1 gene, located on chromosome 11q13, is associated with cell proliferation and differentiation, which fulfills a specific role during the cell cycle progression, subsequently affecting the transcription of genes and promoting the growth (G1) phase to the synthesis (S) phase transition of the cell cycle by activating and adhering to cyclin-dependent kinase 4 (CDK4) or cyclin-dependent kinase 6 (CDK6) $[11,12]$. CCND1 encodes a subunit of the holoenzyme complex that phosphorylates the retinoblastoma protein $(\mathrm{Rb})$ by $\mathrm{CDK} 4$ and CDK6. Phosphorylation of $\mathrm{Rb}$ releases transcription factors such as E2F to activate the transcription of genes, whose products are required to entry into $\mathrm{S}$ phase of the cell cycle $[13,14]$. In addition, the accumulating evidences discoveried that increased expression of CCND1 disrupted normal cell cycle process and possibly promoted the development of many malignant cancers, including RCC, which might be closely associated with metastases and the poor prognosis [15-17].

Previous genome-wide association studies (GWAS) have identified many risk loci for RCC, and expression quantitative trait analyses suggested plausible candidate genes at these regions that might contribute to RCC susceptibility [18]. However, some genetic polymorphisms associated with the risk of RCC still did not be found. Considering that CCND1 played an important role in the occurrence of RCC, we hypothesized that the polymorphisms of this gene might act as a potential genetic marker to predict RCC risk and progression. To validate this hypothesis, we genotyped these polymorphisms in a case-control study, including 1,488 cases and 1,677 controls in a Chinese population in the present study. Therefore, SNPs in CCND1 (rs1944129, rs7177, rs9344 and rs678653) were selected and their genetic associations with RCC risk were evaluated to identify whether genetic variants in CCND1 might contribute to the susceptibility of RCC.

\section{RESULTS}

\section{Characteristics of RCC patients and controls}

The frequency distributions of selected characteristics of the 1,488 cases and 1,677 controls were presented in Table 1. No significant differences between the cases and controls with regard to age, sex and family history of cancer was found (all $P>0.05$ ). Nevertheless, there were more subjects with BMI, smokers, drinking status, hypertension patients and diabetics among the cases than among the control subjects $(P=0.008,0.008,0.036$,
$<0.001$ and $<0.001$, respectively). Of 1,488 patients, $64.0 \%$ of the patients were in stage I, whereas $20.0 \%$, $8.0 \%$ and $8.0 \%$ were found to have stage II, III and IV diseases, respectively. The percent of nuclear grade from I to IV was $21.0 \%, 50.0 \%, 22.0 \%$ and $7.0 \%$ respectively. Moreover, the majority of patients $(84.0 \%)$ had the conventional RCC. These variables were further adjusted with multivariate logistic regression models.

\section{Association between RCC risk and genetic polymorphisms of CCND1}

Genotype and allele distributions of the remaining four tSNPs in the patients and controls were detailed in Table 2. All genotype frequencies in controls and patients both conformed to HWE. No significant differences in genotype and allele distributions of rs9344 and rs678653 polymorphisms were observed between the cases and controls $(P=0.247$ and $P=0.120$, respectively). However, the genotype frequencies for rs1944129 and rs7177 polymorphisms between the cases and controls were significantly different $(P=0.015$ and $P=0.018$, respectively). Based on logistic regression analysis, when using the rs1944129 AA genotype as the reference, the GG and AG+CC genotype of the SNP rs1944129 were associated with a significantly increased risk of RCC (GG vs $\mathrm{AA}$ : adjusted $\mathrm{OR}=1.56,95 \% \mathrm{CI}=1.15-2.13, P=$ $0.005 ; \mathrm{AG}+\mathrm{CC}$ vs AA: adjusted $\mathrm{OR}=1.17,95 \% \mathrm{CI}=1.01$ $-1.35, P=0.032$ ). In addition, individual with $\mathrm{CC}$ and $\mathrm{AC}+\mathrm{CC}$ genotype in rs 7177 had a significantly increased susceptibility to RCC occurrence (CC vs AA: adjusted $\mathrm{OR}=1.83,95 \% \mathrm{CI}=1.08-3.10, P=0.024 ; \mathrm{AC}+\mathrm{CC}$ vs AA: adjusted $\mathrm{OR}=1.17,95 \% \mathrm{CI}=1.00-1.37, P=$ 0.045 ), compared with individuals carrying rs7177 AA genotype. Similarly, a significantly increased risk of RCC was found in the genotype rs9344 GG compared with the AA genotype (adjusted $\mathrm{OR}=1.24,95 \% \mathrm{CI}=1.00-1.52$, $P=0.046)$.

\section{Combined analysis between CCND1 polymorphisms and RCC susceptibility}

Because two polymorphisms (rs1944129 and rs7177) appeared to be associated with an increased risk of RCC, we combined two SNPs based on the number of the risk alleles, and evaluated the potential interactions of the polymorphisms on the risk of RCC. As listed in Table 3 , statistical significance was observed in the combined analysis of risk alleles. Furthermore, we classified the risk alleles into two groups according to the number of risk alleles. We found that the risk of RCC was significantly increased in subjects that carried 2-4 risk alleles compared to those carrying 0-1 risk alleles (adjusted $\mathrm{OR}=1.35$, $95 \% \mathrm{CI}=1.15-1.58, P<0.001)$. However, As shown in Table 4, there was no correlation between the combined genotypes in the clinical stage and grade. We found that 
Table 1: Distribution of selected variables between the renal cell cancer cases and the control subjects

\begin{tabular}{|c|c|c|c|c|c|}
\hline \multirow{2}{*}{ Variables } & \multicolumn{2}{|c|}{ Cases $(n=1488)$} & \multicolumn{2}{|c|}{ Controls $(n=1677)$} & \multirow{2}{*}{ P -value } \\
\hline & $\mathbf{N}$ & $\%$ & $\mathbf{N}$ & $\%$ & \\
\hline $\begin{array}{l}\text { Age }(\text { mean } \pm S D), \\
\text { years }\end{array}$ & \multicolumn{2}{|c|}{$56.7 \pm 12.0$} & \multicolumn{2}{|c|}{$57.8 \pm 12.0$} & 0.176 \\
\hline$<60$ & 893 & 60.01 & 975 & 58.14 & 0.285 \\
\hline$\geq 60$ & 595 & 39.99 & 702 & 41.86 & \\
\hline \multicolumn{6}{|l|}{ Sex } \\
\hline Male & 942 & 63.31 & 1113 & 66.37 & 0.072 \\
\hline Female & 546 & 36.69 & 564 & 33.63 & \\
\hline $\begin{array}{l}\text { BMI (mean } \pm \text { SD), } \\
\mathrm{kg} / \mathrm{m}^{2}\end{array}$ & \multicolumn{2}{|c|}{$24.1 \pm 2.9$} & \multicolumn{2}{|c|}{$23.9 \pm 3.1$} & 0.013 \\
\hline$<24$ & 730 & 49.06 & 902 & 53.79 & 0.008 \\
\hline$\geq 24$ & 758 & 50.94 & 775 & 46.21 & \\
\hline \multicolumn{6}{|l|}{ Smoking status } \\
\hline Never & 922 & 61.96 & 1115 & 66.49 & 0.008 \\
\hline Ever & 566 & 38.04 & 562 & 33.51 & \\
\hline \multicolumn{6}{|l|}{ Drinking status } \\
\hline Never & 1092 & 73.39 & 1285 & 76.62 & 0.036 \\
\hline Ever & 396 & 26.61 & 392 & 23.38 & \\
\hline \multicolumn{6}{|l|}{ Family } \\
\hline No & 1380 & 92.74 & 1535 & 91.53 & 0.208 \\
\hline Yes & 108 & 7.26 & 142 & 8.47 & \\
\hline \multicolumn{6}{|l|}{ Hypertension } \\
\hline No & 907 & 60.95 & 1259 & 75.07 & $<0.001$ \\
\hline Yes & 581 & 39.05 & 418 & 24.93 & \\
\hline \multicolumn{6}{|l|}{ Diabetes } \\
\hline No & 1295 & 87.03 & 1572 & 93.74 & $<0.001$ \\
\hline Yes & 193 & 12.97 & 105 & 6.26 & \\
\hline \multicolumn{6}{|l|}{ Clinical stage } \\
\hline I & 946 & 0.64 & & & \\
\hline II & 303 & 0.20 & & & \\
\hline III & 115 & 0.08 & & & \\
\hline IV & 124 & 0.08 & & & \\
\hline \multicolumn{6}{|l|}{ Grade } \\
\hline I & 319 & 0.21 & & & \\
\hline II & 744 & 0.50 & & & \\
\hline III & 322 & 0.22 & & & \\
\hline IV & 103 & 0.07 & & & \\
\hline
\end{tabular}

(Continued) 


\begin{tabular}{|c|c|c|c|c|c|}
\hline \multirow{2}{*}{ Variables } & \multicolumn{2}{|c|}{ Cases $(n=1488)$} & \multicolumn{2}{|c|}{ Controls $(n=1677)$} & \multirow{2}{*}{$P$-value* } \\
\hline & $\mathbf{N}$ & $\%$ & $\mathbf{N}$ & $\%$ & \\
\hline \multicolumn{6}{|l|}{ Histology } \\
\hline Clear cell & 1250 & 0.84 & & & \\
\hline Papillary & 53 & 0.04 & & & \\
\hline Chromophobe & 79 & 0.05 & & & \\
\hline Unclassified & 106 & 0.07 & & & \\
\hline
\end{tabular}

*Student's t-test for age and BMI distributions between cases and controls; two sided $\chi^{2}$ test for other selected variables between cases and controls.

the frequencies of patients with 2-4 risk alleles were observed no signifiant difference in both the advanced stage of RCC $(31.0 \%)$ and the localized stage $(31.0 \%)$ (adjusted $\mathrm{OR}=0.98,95 \% \mathrm{CI}=0.69-1.39, P=0.897$ ). Moreover, no significant difference was detected in the association between 2-4 risk alleles and the patients with well-differentiated RCC (adjusted OR $=1.18,95 \% \mathrm{CI}=$ $0.89-1.57, P=0.257)$.

\section{Stratified analysis of the two polymorphisms and clinicopathologic characteristics and risk of RCC}

After that, stratification analysis of the two polymorphisms (rs1944129 and rs7177) indicated that the increased risk was more pronounced among younger subjects (adjusted $\mathrm{OR}=1.42,95 \% \mathrm{CI}=1.15-1.75, P=$ 0.001 ), nonsmokers (adjusted $\mathrm{OR}=1.44,95 \% \mathrm{CI}=1.18$ - 1.76, $P<0.001$ ), nondrinkers (adjusted $\mathrm{OR}=1.36,95 \%$ $\mathrm{CI}=1.13-1.63, P=0.001)$, patients without a family history of RCC (adjusted OR $=1.34,95 \% \mathrm{CI}=1.13$ $1.58, P=0.001$ ), and nondiabetes (adjusted $\mathrm{OR}=1.42$, $95 \% \mathrm{CI}=1.20-1.67, P<0.001)($ Table 5$)$.

\section{Association between CCND1 rs1944129 polymorphism and clinicopathological characteristics of RCC patients}

We then investigated the association of the CCND1 rs1944129 polymorphism and clinicopathological characteristics of RCC patients. As shown in Table 6, in patients with stage I, stage II and stage III and moderately (grade I and II) or poorly differentiated (grade III and IV) nuclear grade, no significant difference was observed. However, compared with individuals carrying $\mathrm{AG}+\mathrm{GG}$, the rs1944129 AA was significantly more frequent in patients with clinical stage IV (adjusted OR $=52.14$; $95 \% \mathrm{CI}=51.22-3.75, P=0.029$ ).

\section{DISCUSSION}

In the present study, we evaluated the associations between CCND1 polymorphisms and the susceptibility and clinicopathological development of RCC in a Chinese population. Our results suggested that genotype variation of rs1944129 polymorphism had a significantly increased risk for RCC, especially in the patients with GG or AG+GG genotypes. Similarly, we also found that individuals with rs7177 genotype variation was associated with increased RCC risk, mainly in those with $\mathrm{CC}$ or $\mathrm{AC}+\mathrm{CC}$ genotypes. However, we could not find any significant difference in the rs 9344 and rs678653 genotype frequency between the RCC patients and controls. In addition, because both rs1944129 and rs7177 genotypes had statistically significantly increased risk of RCC, we evaluated rs1944129 and rs7177 together and found that individuals carrying the two or three risk alleles had a significantly increased RCC risk. As far as we know, this study was the first to evaluate the role of the CCND1 polymorphisms in the aetiology of RCC.

As a critical regulatory protein of 295 amino acids, CCND1 gene consists of five exons and four introns and nencodes cyclin $\mathrm{D}$, which affects the transcription of genes and promotes the transition from G1 to S phase of the cell cycle during cell differentiation $[19,20]$. It has been demonstrated that cell cycle regulation appears to play a vital role in cell proliferation, differentiation and apoptosis in the evolution and development of several types of cancer, where it can influence the inhibition of mitochondrial metabolism, regulation of transcription factor signaling via a DNA-bound form, the induction of chromosomal instability and so on [21]. Single nucleotide polymorphisms (SNPs) were reported to change the structure of the genome and influence the protein expression and function, contributing to abnormal cell proliferation and an increased risk of cancer [22]. Of the SNPs in CCND1, the mutation is the common and the some allele changes do lead to an alternatively spliced transcript of CCND1, which facilitates the passage of the variant cell through the G1-S checkpoint and rapid proliferation, ultimately resulting in cancer development [23]. Overexpression or disordered regulation of CCND1 is predominantly correlated with early cancer onset, shorter cancer patient survival and increased metastases, and disrupts normal cell cycle process [24-26]. 
Table 2: The basic information of the genotyped polymorphisms in four SNPs in the CCND1 associated with the RCC risk

\begin{tabular}{|c|c|c|c|c|c|c|}
\hline \multirow{2}{*}{ Polymorphisms } & \multicolumn{2}{|c|}{ Cases $(n=1488)$} & \multicolumn{2}{|c|}{ Controls $(n=1677)$} & \multirow{2}{*}{$\mathbf{P *}$} & \multirow{2}{*}{ Adjusted OR (95\% CI)* } \\
\hline & $\mathbf{N}$ & $\%$ & $\mathbf{N}$ & $\%$ & & \\
\hline \multicolumn{7}{|l|}{ rs1944129 } \\
\hline AA & 824 & 55.4 & 992 & 59.2 & 0.015 & 1.00 (reference) \\
\hline $\mathrm{AG}$ & 557 & 37.4 & 600 & 35.8 & 0.145 & $1.12(0.96-1.30)$ \\
\hline GG & 107 & 7.2 & 85 & 5.1 & 0.005 & $1.56(1.15-2.13)$ \\
\hline $\mathrm{AG}+\mathrm{GG}$ & 664 & 44.6 & 685 & 40.8 & 0.032 & 1.17(1.01-1.35) \\
\hline A allele & 2205 & 74.1 & 2584 & 77.0 & 0.006 & \\
\hline G allele & 771 & 25.9 & 770 & 23.0 & & \\
\hline \multicolumn{7}{|l|}{ rs7177 } \\
\hline AA & 1025 & 68.9 & 1205 & 71.9 & 0.018 & 1.00 (reference) \\
\hline $\mathrm{AC}$ & 423 & 28.4 & 448 & 26.7 & 0.117 & $1.14(0.97-1.33)$ \\
\hline $\mathrm{CC}$ & 40 & 2.7 & 24 & 1.4 & 0.024 & $1.83(1.08-3.10)$ \\
\hline $\mathrm{AC}+\mathrm{CC}$ & 463 & 31.1 & 472 & 28.1 & 0.045 & 1.17(1.00-1.37) \\
\hline A allele & 2473 & 83.1 & 2858 & 85.2 & 0.021 & \\
\hline C allele & 503 & 16.9 & 496 & 14.8 & & \\
\hline \multicolumn{7}{|l|}{ rs9344 } \\
\hline AA & 429 & 28.8 & 520 & 31.0 & 0.247 & 1.00 (reference) \\
\hline $\mathrm{AG}$ & 740 & 49.7 & 831 & 49.6 & 0.203 & $1.11(0.94-1.32)$ \\
\hline GG & 319 & 21.4 & 326 & 19.4 & 0.046 & $1.24(1.00-1.52)$ \\
\hline $\mathrm{AG}+\mathrm{GG}$ & 1059 & 71.2 & 1157 & 69.0 & 0.098 & $1.17(0.98-1.34)$ \\
\hline A allele & 1598 & 53.7 & 1871 & 55.8 & 0.096 & \\
\hline G allele & 1378 & 46.3 & 1483 & 44.2 & & \\
\hline \multicolumn{7}{|l|}{ rs678653 } \\
\hline $\mathrm{CC}$ & 1079 & 72.5 & 1259 & 75.1 & 0.120 & 1.00 (reference) \\
\hline $\mathrm{CG}$ & 380 & 25.5 & 397 & 23.7 & 0.283 & $1.10(0.93-1.29)$ \\
\hline GG & 29 & 1.9 & 21 & 1.3 & 0.199 & $1.47(0.82-2.65)$ \\
\hline $\mathrm{CG}+\mathrm{GG}$ & 409 & 27.5 & 418 & 24.9 & 0.192 & $1.11(0.95-1.31)$ \\
\hline C allele & 2538 & 85.3 & 2915 & 86.9 & 0.061 & \\
\hline $\mathrm{G}$ allele & 438 & 14.7 & 439 & 13.1 & & \\
\hline
\end{tabular}

*Adjusted for age, sex, BMI, smoking status, drinking status, diabetes and hypertension in logistic regression model. CI, confidence interval; OR, odds ratio.

During the past few years, it has been previously reported that high levels of activity of CCND1 polymorphisms could affect the development and progression of certain cancers of humans, such as esophageal squamous cell carcinoma [27], lung cancer [28], breast cancer [29], pancreatic cancer [30] and other cancer types in different ethnicities. For example, Sabir et al. suggested that the CCND1 G/A rs9344 polymorphism was associated with the early onset of head andneck cancer and might contribute to head andneck cancer susceptibility in a Pakistani population [31]. In addition, the A allele of CCND1 rs9344 polymorphism might serve as a risky marker in early detection and prediction for CRC in Taiwan by Huang et al [32]. Nevertheless, studies on the association between genetic variants in CCND1 and susceptibility of RCC were insufficient. With 
Table 3: Analysis between combined risk alleles and RCC Susceptibility

\begin{tabular}{|c|c|c|c|c|c|c|}
\hline \multirow{2}{*}{ rs1944129 and rs7177 } & \multicolumn{2}{|c|}{ Cases $(n=1488)$} & \multicolumn{2}{|c|}{ Controls $(n=1677)$} & \multirow{2}{*}{$\mathbf{P} *$} & \multirow{2}{*}{ Adjusted OR (95\% CI)* } \\
\hline & $\mathbf{N}$ & $\%$ & $\mathbf{N}$ & $\%$ & & \\
\hline \multicolumn{7}{|l|}{ Number of risk alleles } \\
\hline 0 & 768 & 51.6 & 893 & 53.2 & & 1.00 (reference) \\
\hline 1 & 265 & 17.8 & 370 & 22.1 & 0.127 & $0.86(0.71-1.04)$ \\
\hline 2 & 375 & 25.2 & 358 & 21.3 & 0.018 & $1.24(1.04-1.48)$ \\
\hline 3 & 61 & 4.1 & 44 & 2.6 & 0.009 & $1.72(1.15-2.58)$ \\
\hline 4 & 19 & 1.3 & 12 & 0.7 & 0.280 & $1.52(0.71-3.24)$ \\
\hline \multicolumn{7}{|l|}{ Recombined groups } \\
\hline $0-1$ & 1033 & 69.4 & 1263 & 75.3 & & 1.00 (reference) \\
\hline $2-4$ & 455 & 30.6 & 414 & 24.7 & $<0.001$ & $1.35(1.15-1.58)$ \\
\hline
\end{tabular}

*Two-sided x2 test for either genotype distributions or allele frequencies between the cases and controls. Adjusted for age, smoking status, drinking status and family history of cancer in logistic regression model; 95\% CI: 95\% confidence interval. The $0-4$ represents the numbers of risk alleles within the combined genotypes; the risk alleles used for the calculation were the rs1944129 and rs7177 alleles.

Table 4: Association between the combined genotypes of rs1944129 and rs7177 polymorphisms and clinicopathologic characteristics of renal cell carcinoma

\begin{tabular}{|c|c|c|c|c|c|c|}
\hline \multirow{3}{*}{ Variables } & \multicolumn{4}{|c|}{ Risk allele } & \multirow{3}{*}{$\mathbf{P *}$} & \multirow{3}{*}{ Adjusted OR (95\% CI)* } \\
\hline & \multicolumn{2}{|c|}{ 0-1 } & \multicolumn{2}{|c|}{$2-4$} & & \\
\hline & $\mathbf{N}$ & $\%$ & $\mathbf{N}$ & $\%$ & & \\
\hline \multicolumn{7}{|c|}{ Clinical stage } \\
\hline $\mathrm{I}+\mathrm{II}$ & 867 & 69 & 382 & 31 & & 1.00 (reference) \\
\hline $\mathrm{III}+\mathrm{IV}$ & 166 & 69 & 73 & 31 & 0.897 & $0.98(0.69-1.39)$ \\
\hline \multicolumn{7}{|l|}{ Grade } \\
\hline $\mathrm{I}+\mathrm{II}$ & 745 & 70 & 318 & 30 & & 1.00 (reference) \\
\hline III + IV & 288 & 68 & 137 & 32 & 0.257 & $1.18(0.89-1.57)$ \\
\hline
\end{tabular}

*Adjusted for age, sex, BMI, smoking status, drinking status, diabetes and hypertension in logistic regression model. CI, confidence interval; OR, odds ratio.

a growing interest in the association between the CCND1 polymorphisms and RCC risk, several studies have tested the hypothesis that the CCND1 polymorphisms were associated with RCC risk [33-35], but the findings remained inconsistent. Therefore, the present study was performed to investigate whether these polymorphisms could influence the susceptibility of RCC.

In our study, we genotyped four polymorphisms in CCND1 to explore the association between CCND1 genetic variants and RCC susceptibility in Chinese population. The CCND1 rs1944129 and rs7177 significantly differed between RCC patients and control participants, indicating that the risk of RCC was increased in participants with the $\mathrm{GG}$ or $\mathrm{AG}+\mathrm{GG}$ genotypes of rs 1944129 and $\mathrm{CC}$ or $\mathrm{AC}+\mathrm{CC}$ genotypes of rs 7177. The further analysis of the combining risk alleles showed that the group of patients with 2-4 risk alleles was more susceptible to RCC compared with those with 0-1 risk alleles. Environmental and epidemiological factor also had certain effects on the risk of RCC according to our stratification analyses in combination genotypes of CCND1 rs1944129 and rs7177. Age, sex, BMI, smoking status, drinking status, the history of diabetes and hypertension were all related with the RCC susceptibility, implying that the interaction of the environment, hereditary background and genetic variants might be a complex system contributed to the occurrence of RCC [36, 37]. Interestingly, stratification analyses of the association 
Table 5: Association between the combined genotypes of rs1944129 and rs7177 polymorphisms and clear cell renal cell carcinoma in stratified analysis

\begin{tabular}{|c|c|c|c|c|c|c|}
\hline \multirow{3}{*}{ Variables } & \multicolumn{4}{|c|}{ Risk allele } & \multirow{3}{*}{$\mathbf{P *}$} & \multirow{3}{*}{$\begin{array}{c}\text { Adjusted OR } \\
(95 \% \text { CI })^{*}\end{array}$} \\
\hline & \multicolumn{2}{|c|}{$0-1$} & \multicolumn{2}{|c|}{$2-4$} & & \\
\hline & Case(n,\%) & Control(n,\%) & $\operatorname{Case}(n, \%)$ & $\operatorname{Control}(n, \%)$ & & \\
\hline \multicolumn{7}{|l|}{ Age } \\
\hline$<60$ & $616(59.6)$ & $741(58.7)$ & $277(60.9)$ & $234(56.5)$ & 0.001 & $1.42(1.15-1.75)$ \\
\hline$\geq 60$ & $417(40.4)$ & $522(41.3)$ & $178(39.1)$ & $180(43.5)$ & 0.064 & $1.27(0.98-1.64)$ \\
\hline \multicolumn{7}{|l|}{ Sex } \\
\hline Male & $650(65.9)$ & $832(65.9)$ & $292(64.2)$ & $281(67.9)$ & 0.014 & $1.42(1.07-1.86)$ \\
\hline Female & $383(37.1)$ & $431(34.1)$ & $163(35.8)$ & $133(32.1)$ & 0.008 & $1.31(1.07-1.61)$ \\
\hline \multicolumn{7}{|l|}{ BMI } \\
\hline$<24$ & $516(50.0)$ & $683(54.1)$ & $214(47.0)$ & $219(52.9)$ & 0.029 & $1.29(1.03-1.62)$ \\
\hline$\geq 24$ & $517(50.0)$ & $580(45.9)$ & $241(53.0)$ & $195(47.1)$ & 0.003 & $1.42(1.13-1.79)$ \\
\hline \multicolumn{7}{|c|}{ Smoking status } \\
\hline Never & $635(61.5)$ & $845(66.9)$ & $287(63.1)$ & $27065.2)$ & $<0.001$ & $1.44(1.18-1.76)$ \\
\hline Ever & $398(38.5)$ & $418(33.1)$ & $168(36.9)$ & $144(34.8)$ & 0.1 & $1.26(0.96-1.66)$ \\
\hline \multicolumn{7}{|c|}{ Drinking status } \\
\hline Never & $751(72.7)$ & $964(76.3)$ & $341(74.9)$ & $321(77.5)$ & 0.001 & $1.36(1.13-1.63)$ \\
\hline Ever & $282(27.3)$ & $299(23.7)$ & $114(25.1)$ & $93(22.5)$ & 0.105 & $1.33(0.94-1.87)$ \\
\hline \multicolumn{7}{|l|}{ Family } \\
\hline No & $960(92.9)$ & $1156(91.5)$ & $420(92.3)$ & $379(91.5)$ & 0.001 & $1.34(1.13-1.58)$ \\
\hline Yes & $73(7.1)$ & $107(8.5)$ & $35(7.7)$ & $35(8.5)$ & 0.114 & $1.65(0.89-3.08)$ \\
\hline \multicolumn{7}{|c|}{ Hypertension } \\
\hline No & $638(61.8)$ & $949(75.1)$ & $269(59.1)$ & $310(74.9)$ & 0.008 & $1.30(1.07-1.58)$ \\
\hline Yes & 395 (38.2) & $314(24.9)$ & $186(40.9)$ & $104(25.1)$ & 0.008 & $1.47(1.10-1.97)$ \\
\hline \multicolumn{7}{|l|}{ Diabetes } \\
\hline No & 877 (84.9) & $1185(93.8)$ & 418 (91.9) & $387(93.5)$ & $<0.001$ & $1.42(1.20-1.67)$ \\
\hline Yes & $156(15.1)$ & $78(6.2)$ & $37(8.1)$ & $27(6.5)$ & 0.324 & $0.74(0.40-1.35)$ \\
\hline
\end{tabular}

*Two-sided $\chi 2$ test for number of risk alleles in cases and controls; 95\% CI: 95\% confidence. Adjusted for age, pack-years of smoking, drinking status, and family history of cancer in logistic regression model.

between combination genotypes of CCND1 rs1944129 and rs7177 and the risk of RCC revealed a little different in smokers status, drinking status, history of hypertension or diabetes compared with that of risk alleles. In addition, compared with individuals carrying $\mathrm{AG}+\mathrm{GG}$, the rs 1944129 AA was significantly more frequent in patients with clinical stage IV.

In reviewing the results of this study, several limitations should be taken into consideration in our present study, some of which cannot be overcame. First, our study was a retrospective hospital-based case-control design, we could not completely rule out the possibility of selection bias for subjects who might have been associated with a particular genotype. Second, the lack of detailed survival data from all participants limited our ability to explore the association between these SNPs in CCND1 and prognosis and survival of RCC. Third, the sample size was relatively small, which reduced the statistical power of combined analysis and stratification, particularly for gene-environment interaction analyses. What's more, 
Table 6: The association of CCND1 rs1944129 polymorphism and clinicopathologic characteristics of ccRCC patients

\begin{tabular}{|c|c|c|c|c|c|c|}
\hline \multirow{3}{*}{ Variables } & \multicolumn{4}{|c|}{ Risk allele } & \multirow{3}{*}{$P^{*}$} & \multirow{3}{*}{ Adjusted OR (95\% CI)* } \\
\hline & \multicolumn{2}{|c|}{$\mathbf{A A}$} & \multicolumn{2}{|c|}{$\mathbf{A G}+\mathbf{G G}$} & & \\
\hline & $\mathbf{N}$ & $\%$ & $\mathbf{N}$ & $\%$ & & \\
\hline Clinical stage & 824 & & 664 & & & \\
\hline I & 520 & 63.1 & 426 & 64.2 & & 1.00 (reference) \\
\hline II & 168 & 20.4 & 135 & 20.3 & 0.113 & $0.77(0.56-1.06)$ \\
\hline III & 59 & 7.2 & 56 & 8.4 & 0.611 & $0.89(0.56-1.40)$ \\
\hline IV & 77 & 9.3 & 47 & 7.1 & 0.029 & $0.56(0.33-0.94)$ \\
\hline \multicolumn{7}{|l|}{ Grade } \\
\hline I & 175 & 21.20 & 144 & 21.7 & & 1.00 (reference) \\
\hline II & 409 & 49.60 & 335 & 50.5 & 0.639 & $0.96(0.81-1.14)$ \\
\hline III & 178 & 21.60 & 144 & 21.7 & 0.670 & $0.92(0.62-1.36)$ \\
\hline IV & 62 & 7.50 & 41 & 6.2 & 0.818 & $0.91(0.42-1.99)$ \\
\hline
\end{tabular}

*Two-sided $\chi 2$ test for number of alleles in cases and controls; $95 \%$ CI: 95\% confidence interval. Adjusted for age, BMI, gender, smoking status, drinking status and history of hypertension and diabetes in logistic regression model.

our findings needed to be further validated by other highquality studies with a more comprehensive design in subsequent studies.

\section{MATERIALS AND METHODS}

\section{Ethics statement}

The study was approved by the Institutional Review Board of the Nanjing Medical University, Nanjing, China. At recruitment, a written informed consent was obtained from all participants involved in this study.

\section{Study population}

The present ongoing case-control study of RCC, including 1,488 patients with RCC and a group of 1,677 cancer-free controls was conducted in the Department of Urology, the First Affiliated Hospital of Nanjing Medical University, Nanjing, China, starting in September 2003. In brief, all subjects were genetically unrelated ethnic Han Chinese recruited coming from different families and had no blood relationship. All of the incident RCC patients were newly diagnosed with histopathologically confirmed by two pathologists independently and were identified by reviewing the medical records to ensure no prior history of other cancers or metastasized cancer for other or unknown origins or previously subjected to chemotherapy or radiotherapy, and were consecutively recruited without restriction of age and sex. The cancerfree controls who consisted of randomly-selected volunteers, were seeking health care in the outpatient departments at the hospital matched to the cases' sex and age (65 years) on frequency. In the present study, nonsmokers were defined as those who smoked less one cigarette per day and less one year over their lifetime and all others were considered as smokers. In addition, drinkers were those who drank at least three times per week for a period lasting more than six months and the rest were defined as never drinkers. Family history of cancer was considered as any occurrence of cancer in first-degree relatives (parents, siblings, or children). The tumor stage was determined using the international tumor-node-metastasis (TNM) classification system and graded according to World Health Organization criteria. Based on the American Joint Committee on Cancer (AJCC), the disease stage was divided into localized group (stage I and stage II) and advanced group (stage III and stage IV) by the assessment of the Fuhrman scale. After signing the agreement, about $5 \mathrm{ml}$ venous blood samples for genomic DNA extraction were obtained from each subject.

\section{SNP selection}

According to HapMap data (http://hapmap.ncbi. nlm.nih.gov/) and PubMed data (http://www.ncbi.nlm. nih.gov/projects/SNP/), some potentially functional tSNPs 
in CCND1 gene were choosed. Minor allele frequency (MAF) of each gene polymorphism was more than 5\% in the Han Chinese population. When some of the SNPs were in complete linkage disequilibrium $\left(\mathrm{r}^{2}=1\right)$, only one SNP was selected for genotyping. Finally, we included four SNPs in CCND1 (rs1944129, rs7177, rs9344 and rs678653), which were recently found to be significantly associated with some malignancies in the Chinese population $[31,32,38]$.

\section{DNA extraction and polymorphism genotyping}

Total genomic DNA was seperated and purified from the peripheral blood lymphocytes by proteinase $\mathrm{K}$ digestion and phenol-chloroform extraction, according to the manufacturer's directions (GoldMag Co. Ltd. Xian, China). The genotyping of CCND1 polymorphisms was performed by pre-designed TaqMan SNP Genotyping Assays (Applied Biosystems, Foster City, CA, USA). The sequence of primers and probes for the SNP were available on request. Amplification was executed under the following melting steps: $2 \mathrm{~min}$ at $50^{\circ} \mathrm{C}, 10 \mathrm{~min}$ at $95^{\circ} \mathrm{C}$, followed by 45 cycles of $95^{\circ} \mathrm{C}$ for $15 \mathrm{sec}$ and $1 \mathrm{~min}$ at $60^{\circ} \mathrm{C}$. According to the manufacturer's instructions, amplifications and analysis were adopted by the genotyping assay in the 384-well ABI 7900HT Real-Time PCR System (Applied Biosystems) and the SDS 2.4 software were used to automatically collect and analyze the data for subsequently allelic discrimination in a blind manner. In order to ensure the accuracy of genotyping, positive controls by sequencing and negative controls without DNA were used. Furthermore, four negative controls were included in each 384-well plate for quality control and samples making up more than $5 \%$ of the cases and controls were randomly selected for repeated genotyping for confirmation with a reproducibility of $100 \%$.

\section{Statistical analysis}

Student's t-test was performed to test the differences in continuous variables such as age and BMI. Pearson's chi-square test was performed to analyze the differences in categorical variables such as gender, smoking status, drinking status, and in the frequency distribution of CCND1 polymorphisms alleles and genotypes between the cases and controls. The allele frequencies of the CCND1 polymorphisms in the controls were tested against departure from Hardy-Weinberg equilibrium (HWE) by the goodness-of-fit Chi-square test. The adjusted odds ratios (ORs) and 95\% confidence intervals (CIs) from unconditional univariate and multivariate logistic regression analysis with the adjustment for possible confounders were used to evaluate the associations between the CCND1 polymorphisms and the risk of RCC. $P$ value was deemed as statistically significant when less than 0.05. All the statistical analyses were carried out with the SPSS version 22.0 (SPSS Inc., Chicago, IL, USA) with two-sided $P$ values.

\section{CONCLUSION}

Overall, we investigated an association between CCND1 polymorphisms and susceptibility, clinical characteristics of RCC patients in a large sample population. Our case-control study indicated that CCND1 rs1944129 and rs7177 were the genetic susceptibility factors for the pathogenesis of RCC in Chinese population, and the combination of risk alleles were significantly associated with the elevated risk of RCC. Although the associations appeared to be statistically significant in our population, these findings need to be further validated by other large independent population-base studies with a more comprehensive design and additional available data to investigate the specific function of CCND1 polymorphisms in the development of RCC.

\section{ACKNOWLEDGMENTS}

This study was supported by the National Natural Science Funding of China (No. 81402321).

\section{CONFLICTS OF INTEREST}

We declare that we have no conflicts of interest.

\section{REFERENCES}

1. Siegel RL, Miller KD, Jemal A. Cancer Statistics, 2017. CA Cancer J Clin. 2017; 67:7-30.

2. Porta C, Bellmunt J, Eisen T, Szczylik C, Mulders P. Treating the individual: The need for a patient-focused approach to the management of renal cell carcinoma. Cancer Treat Rev. 2010; 36:16-23.

3. Ljungberg B, Campbell SC, Choi HY, Jacqmin D, Lee JE, Weikert S, Kiemeney LA. The epidemiology of renal cell carcinoma. Eur Urol. 2011; 60:615-621.

4. Chow WH, Dong LM, Devesa SS. Epidemiology and risk factors for kidney cancer. Nat Rev Urol. 2010; 7:245-257.

5. Vineis P, Alavanja M, Buffler P, Fontham E, Franceschi S, Gao YT, Gupta PC, Hackshaw A, Matos E, Samet J, Sitas F, Smith J, Stayner L, et al. Tobacco and cancer: recent epidemiological evidence. J Natl Cancer Inst. 2004; 96:99-106.

6. Adams KF, Leitzmann MF, Albanes D, Kipnis V, Moore SC, Schatzkin A, Chow WH. Body size and renal cell cancer incidence in a large US cohort study. Am J Epidemiol. 2008; 168:268-277. 
7. Bellocco R, Pasquali E, Rota M, Bagnardi V, Tramacere I, Scotti L, Pelucchi C, Boffetta P, Corrao G, La Vecchia C. Alcohol drinking and risk of renal cell carcinoma: results of a meta-analysis. Ann Oncol. 2012; 23:2235-2244.

8. Huang CY, Chu JS, Pu YS, Yang HY, Wu CC, Chung CJ, Hsueh YM. Effect of urinary total arsenic level and estimated glomerular filtration rate on the risk of renal cell carcinoma in a low arsenic exposure area. J Urol. 2011; 185:2040-2044.

9. Mucci LA, Hjelmborg JB, Harris JR, Czene K, Havelick DJ, Scheike T, Graff RE, Holst K, Möller S, Unger RH, McIntosh C, Nuttall E, Brandt I, et al, and Nordic Twin Study of Cancer (NorTwinCan) Collaboration. Familial Risk and Heritability of Cancer Among Twins in Nordic Countries. JAMA. 2016; 315:68-76.

10. Karim S, Al-Maghrabi JA, Farsi HM, Al-Sayyad AJ, Schulten HJ, Buhmeida A, Mirza Z, Al-Boogmi AA, Ashgan FT, Shabaad MM, NourEldin HF, Al-Ghamdi KB, Abuzenadah A, et al. Cyclin D1 as a therapeutic target of renal cell carcinoma- a combined transcriptomics, tissue microarray and molecular docking study from the Kingdom of Saudi Arabia. BMC Cancer. 2016; 16:741.

11. Zwijsen RM, Wientjens E, Klompmaker R, van der Sman J, Bernards R, Michalides RJ. CDK-independent activation of estrogen receptor by cyclin D1. Cell. 1997; 88:405-415.

12. Bienvenu F, Gascan H, Coqueret O. Cyclin D1 represses STAT3 activation through a Cdk4-independent mechanism. J Biol Chem. 2001; 276:16840-16847.

13. Banerjee D, Ercikan-Abali E, Waltham M, Schnieders B, Hochhauser D, Li WW, Fan J, Gorlick R, Goker E, Bertino JR. Molecular mechanisms of resistance to antifolates, a review. Acta Biochim Pol. 1995; 42:457-464.

14. Butt AJ, Caldon CE, McNeil CM, Swarbrick A, Musgrove EA, Sutherland RL. Cell cycle machinery: links with genesis and treatment of breast cancer. Adv Exp Med Biol. 2008; 630:189-205.

15. Nakamura Y, Felizola SJ, Kurotaki Y, Fujishima F, McNamara KM, Suzuki T, Arai Y, Sasano H. Cyclin D1 (CCND1) expression is involved in estrogen receptor beta (ERbeta) in human prostate cancer. Prostate. 2013; 73:590-595.

16. Troncone G, Volante M, Iaccarino A, Zeppa P, Cozzolino I, Malapelle U, Palmieri EA, Conzo G, Papotti M, Palombini L. Cyclin D1 and D3 overexpression predicts malignant behavior in thyroid fine-needle aspirates suspicious for Hurthle cell neoplasms. Cancer. 2009; 117:522-529.

17. Abramson VG, Troxel AB, Feldman M, Mies C, Wang Y, Sherman L, McNally S, Diehl A, Demichele A. Cyclin D1b in human breast carcinoma and coexpression with cyclin D1a is associated with poor outcome. Anticancer Res. 2010; 30:1279-1285.

18. Scelo G, Purdue MP, Brown KM, Johansson M, Wang Z, Eckel-Passow JE, Ye Y, Hofmann JN, Choi J, Foll M,
Gaborieau V, Machiela MJ, Colli LM, et al. Genome-wide association study identifies multiple risk loci for renal cell carcinoma. Nat Commun. 2017; 8:15724.

19. Betticher DC, Thatcher N, Altermatt HJ, Hoban P, Ryder WD, Heighway J. Alternate splicing produces a novel cyclin D1 transcript. Oncogene. 1995; 11:1005-1011.

20. Ekholm SV, Reed SI. Regulation of G(1) cyclin-dependent kinases in the mammalian cell cycle. Curr Opin Cell Biol. 2000; 12:676-684.

21. Pestell RG. New roles of cyclin D1. Am J Pathol. 2013; 183:3-9.

22. Zhang L, Chen LM, Wang MN, Chen XJ, Li N, Huang YD, Chen M. The G894t, T-786c and 4b/a polymorphisms in Enos gene and cancer risk: a meta-analysis. J Evid Based Med. 2014; 7:263-269.

23. Solomon DA, Wang Y, Fox SR, Lambeck TC, Giesting S, Lan Z, Senderowicz AM, Conti CJ, Knudsen ES. Cyclin D1 splice variants. Differential effects on localization, RB phosphorylation, and cellular transformation. J Biol Chem. 2003; 278:30339-30347.

24. Diehl JA. Cycling to cancer with cyclin D1. Cancer Biol Ther. 2002; 1:226-231.

25. Jares P, Colomer D, Campo E. Genetic and molecular pathogenesis of mantle cell lymphoma: perspectives for new targeted therapeutics. Nat Rev Cancer. 2007; 7:750-762.

26. Thomas GR, Nadiminti H, Regalado J. Molecular predictors of clinical outcome in patients with head and neck squamous cell carcinoma. Int J Exp Pathol. 2005; 86:347-363.

27. Ikeguchi M, Sakatani T, Ueta T, Kaibara N. Cyclin D1 expression and retinoblastoma gene protein (pRB) expression in esophageal squamous cell carcinoma. J Cancer Res Clin Oncol. 2001; 127:531-536.

28. Yamanouchi H, Furihata M, Fujita J, Murakami H, Yoshinouchi T, Takahara J, Ohtsuki Y. Expression of cyclin $\mathrm{E}$ and cyclin D1 in non-small cell lung cancers. Lung Cancer. 2001; 31:3-8.

29. Arnold A, Papanikolaou A. Cyclin D1 in breast cancer pathogenesis. J Clin Oncol. 2005; 23:4215-4224.

30. Gansauge S, Gansauge F, Ramadani M, Stobbe H, Rau B, Harada N, Beger HG. Overexpression of cyclin D1 in human pancreatic carcinoma is associated with poor prognosis. Cancer Res. 1997; 57:1634-1637.

31. Sabir M, Baig RM, Mahjabeen I, Kayani MA. Significance of cyclin D1 polymorphisms in patients with head and neck cancer. Int J Biol Markers. 2013; 28:49-55.

32. Huang CY, Tsai CW, Hsu CM, Chang WS, Shui HA, Bau DT. The significant association of CCND1 genotypes with colorectal cancer in Taiwan. Tumour Biol. 2015; 36:6533-6540.

33. Schodel J, Bardella C, Sciesielski LK, Brown JM, Pugh CW, Buckle V, Tomlinson IP, Ratcliffe PJ, Mole DR. 
Common genetic variants at the 11q13.3 renal cancer susceptibility locus influence binding of HIF to an enhancer of cyclin D1 expression. Nat Genet. 2012; 44:420-5.

34. Yu J, Habuchi T, Tsuchiya N, Nakamura E, Kakinuma $\mathrm{H}$, Horikawa Y, Inoue T, Ogawa O, Kato T. Association of the cyclin D1 gene G870A polymorphism with susceptibility to sporadic renal cell carcinoma. J Urol. 2004; 172:2410-2413.

35. Cao Q, Qin C, Ju X, Meng X, Wang M, Zhu J, Li P, Chen J, Zhang Z, Yin C. Chromosome 11q13.3 variant modifies renal cell cancer risk in a Chinese population. Mutagenesis. 2012; 27:345-350.
36. Karami S, Yanik EL, Moore LE, Pfeiffer RM, Copeland G, Gonsalves L, Hernandez BY, Lynch CF, Pawlish K, Engels EA. Risk of Renal Cell Carcinoma Among Kidney Transplant Recipients in the United States. Am J Transplant. 2016; 16:3479-3489.

37. Chow WH, Devesa SS. Contemporary epidemiology of renal cell cancer. Cancer J. 2008; 14:288-301.

38. Petkevicius V, Salteniene V, Juzenas S, Wex T, Link A, Leja M, Steponaitiene R, Skieceviciene J, Kupcinskas L, Jonaitis L, Kiudelis G, Malfertheiner P, Kupcinskas J. Polymorphisms of microRNA target genes IL12B, INSR, CCND1 and IL10 in gastric cancer. World J Gastroenterol. 2017; 23:3480-3487. 